\title{
PENGEMBANGAN LINGKUNGAN BELAJAR BLENDED LEARNING BERBASIS LEARNING MANAGEMENT SYSTEM BAGI MTS MUHAMMADIYAH DI KABUPATEN SOLOK
}

\author{
Hanesman $^{1)}$, Muhammad Adri' ${ }^{2)}$, Ika Parma Dewi ${ }^{3)}$, Putra Jaya ${ }^{4)}$ \\ ${ }^{1,2,3,4}$ Prodi Pendidikan Teknik Informatika, Fakultas Teknik, Universitas Negeri Padang \\ E-mail : ${ }^{1}$ hanesman@ft.unp.ac.id, ${ }^{2}$ mhd.adri@unp.ac.id, ${ }^{3}$ ika_parma@ft.unp.ac.id, \\ putrajaya5316@gmail.com
}

\begin{abstract}
The absence of ICT Subjects in the 2013 National Curriculum requires teachers to be able to internalize them in every subject taught, one of them is by providing ICT-based teaching resources, so students will be able to improve ICT skills through the learning process. So it takes real effort from the school to facilitate this learning process, one of which is through LMS-based Blended Learning (BL). This effort to adopt this technology into education is also carried out by private education institutions, including MTs. Muhammadiyah (MTS.M) in Solok Regency,and realizes it is very urgent to increase the competitiveness and the quality of its education, To achieving this goal, the BL environment is train and build. The experimental method is used to see the improvement of teacher knowledge and skills in LMSbased BL using ADDIE model, which begins with a survey of school readiness and teacher competencies in BL, then continues with the LMS-based BL training activities for 30 teachers from 9 MTs.M. Pre and Post Training Questionnaire design is used in data collection. The results of this research data show an increase in teacher competence in LMS-based BL, with $70 \%$ on Medium and Advance ICT Skill for BL
\end{abstract}

Keyword: Industrial Revolution 4.0, Learning Environment, Blended Learning, Learning Management System, MTs.Muhamamdiyah

\section{PENDAHULUAN}

Keterampilan Teknologi Informasi dan Komunikasi (TIK) pada Kurikulum Nasional 2013 [1], sudah menjadi keterampilan dasar yang harus dikuasai guru, karena keterampilan TIK sudah "embedded" di dalam semua mata pelajaran, sehingga tidak lagi menjadi satu mata pelajaran yang diajarkan kepada siswa, yang menjadikan keterampilan TIK sebagai keterampilan yang terinternalisasi pada seorang guru, yang akan menjadi fasilitator bagi anak didik yang diajarnya dalam memanfaatkan TIK yang sesuai dengan kebutuhan dalam mata pelajaran yang dibinanya.

Ketiadaan Mata Pelajaran TIK ini di dalam Kurikulum Nasional 2013, menuntut kompetensi Guru dalam pemanfaatan TIK menjadi lebih tinggi, karena disamping untuk mendukung profesinya sebagai pendidik, sekaligus juga memberikan contoh dan pendampingan kepada para peserta didik dalam pemanfaatan TIK.
Sementara pada sisi lain, kehadiran Revolusi Industri 4.0 (RI 4.0) tidak dapat dihindari, yang menjadi teknologi digital dan TIK sebagai tulang punggung pergerakan industri [2], [3] sehingga perlu upaya yang sungguh-sungguh dalam mempersiapkan sumberdaya manusia bidang TIK yang handal. Oleh karena itu perlu peranan aktif lembaga pendidikan untuk memaksimalkan pemanfaatan TIK di dalam Pendidikan [4], yang salah satu tujuannya agar bisa memperkecil resiko terhadap tantangan yang muncul dari RI 4.0 bagi Pendidikan manusia [5], agar mampu melahirkan lulusan dengan skillyang tidak akan tergantikan oleh mesin dan komputer.

Disruptif teknologi adalah tantangan yang terjadi dalam kehidupan masyarakat yang akan mengubah tata soial, demikian juga dunia pendidikan, akan ada potensi disruptif yang muncul. Secara umum ada dua [4] : pertama disruptif pada aspek kelembagaaan dan pengelolaan pendidikan dan kedua adalah disruptif terhadap gap kualitas anak didik yang dihasilkan 
terhadap tuntutan dunia digital, karena adanya tuntutan akan permintaan professional sumber daya manusia (SDM) yang dipicu oleh transformasi bisnis ke platform digital [6].

Maka salah satu upaya yang dapat dilakukan oleh Lembaga Pendidikan adalah dengan mengadopsi teknologi digital dalam proses pembelajaran sebagai langkah awal dalam memperkenalkan transformasi ke platform digital bagi anak didik, dengan tetap mengutamakan pendekatan pedagogi melalui tatap muka di kelas. Model integrasi teknologi dengan pembelajaran di kelas ini dikenal dengan Blended Learning (BL) [7].

BL dilaksanakan dengan menggabungkan dua lingkungan belajar yaitu pertama: lingkungan online yang dikenal dengan sebutan e-Learning dengan menggunakan sebuah Learning Management System (LMS) sebagai sistem kelola pembelajaran online dan kedua: lingkungan belajar tatap muka di kelas [8].

Maka dengan disruptif teknologi ini, hari ini keterampilan Teknologi Informasi dan Komunikasi (TIK) sudah menjai generic skill, yang harus dikuasai dengan baik oleh pendidik maupun peserta didik dalam bidang apa pun. Bagi tenaga pendidik, keterampilan TIK dapat meningkatkan produktifitas, efisiensi dan efektifitas dalam bekerja, sedangkan bagi peserta didik, keterampilan TIK digunakan dalam pengembangan kompetensi diri, ilmu pengetahuan dan keterampilan dalam era RI 4.0 dan Pendidikan 4.0, hal ini sejalan pernyataan lembaga pendidikan sebagai pemanfaat TIK dan sekaligus penghasil tenaga ahli TIK [9].

Upaya mengadopsi teknologi digital dan komputer ini ke dalam dunia Pendidikan tidak hanya dilakukan oleh Lembaga Pendidikan pemerintah (sekolah negeri) namun juga juga dilakukan oleh lembaga Pendidikan swasta, termasuk MTs. Muhammadiyah (MTs.M) di Kabupaten (Kab.) Solok, yang merupakan bagian dari pendidikan menengah tingkat pertama.

MTs Muhammadiyah Saningbakar, adalah salah satu Madrasah yang dikelola dan dikembangkan melalui swadaya masyarakat. Madrasah ini telah menjawab kebijakan pemberlakuan Kurikulum 2013 dengan mengimplementasikan Kurnas 2013 dan investasi bidang TIK, dalam wujud sarana laboratorium komputer, akses internet telkom speedy dan pengangkatan tenaga bantu bidang TIK, yang semuanya didanai oleh swadaya masyarakat [10]. Sehingga dengan dukungan sarana dan prasarana ini menjadikan MTs. M Saningbakar sebagai salah satu pioneer dalam implementasi TIK dalam pembelajaran. Dengan keberhasilan ini, maka kemudian MTs.M Saningbakar membangun "paguyuban" MTs. Muhammadiyah di Kab. Solok, dengan menjadikan MTs.M ini sebagai contoh bagi MTs.M lainnya.

Maka persatuan MTs.M Kab. Solok ini, melakukan upaya yang sama dalam pengembangan lingkungan belajar Blended Learning berbasis LMS di semua MTs.M di Kab. Solok, sebagai upaya dalam menghadapi RI 4.0 dalam Pendidikan.

\section{PENDEKATAN PEMECAHAN MASALAH}

\section{Metode}

Metode Riset dan pengembangan yang dilakukan menggunakan model instruksional ADDIE [11], yang terdiri dari 5 tahapan prose pengembangan yaitu Analysis, Design, Development, Implementation dan Evaluation.

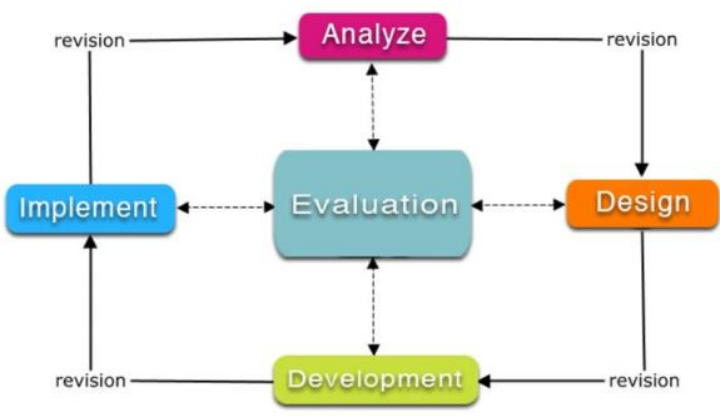

Gambar 1. Model Instruksional ADDIE yang dimodifikasi [12]

Tahapan masing-masing proses pada model ADDIE diimplementasikan dengan langkah sebagai berikut:

\section{Analysis}

Pada tahapan ini dilakukan analisis kesiapan dari MTs.M yang akan mengembangkan lingkungan belajar BL berbasis LMS, baik dari sisi kesiapan SDM maupun Teknologi. Untuk kebutuhan analisis ini digunakan Digital Skill Framework [13]

\section{Design}

Pada tahapan ini dilakukan perancangan lingkungan belajar BL berbasis LMS dengan mengacu kepada Kurikulum Madrasah Tsanawiyah [14][15].

\section{Development}

Pada tahapan ini dilakukan pengembangan BL berbasis LMS dengan menggunakan LMS Open Source Moodle [16], [17],[18]

\section{Implementation}


Implementasi dilakukan dengan mengimplementasika struktur kurikulum MTs ke LMS Moodle dengan studi kasus pengambangan pada satu mata pelajaran yang dibina oleh Guru mata pelajaran.

\section{Evaluation}

Evaluasi dilakukan untuk mengukur sejauh mana keberhasilan pengembangan lingkungan belajar BL berbasis LMS dilakukan oleh para Guru MTs.M di Kab. Solok.

Untuk merealisasikan langkah pengembangan ADDIE di atas, maka dilakukan fase kegiatan berikut :

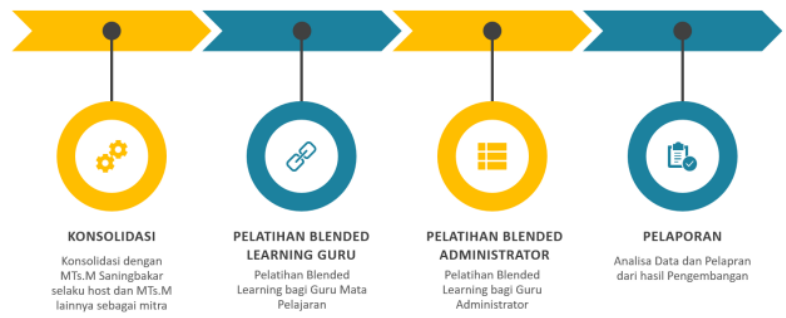

Gambar 2. Fase Pengembangan BL berbasis LMS MTs.M di Kab. Solok.

Gambar 2 memperlihatkan fase kegiatan pengembangan BL berbasis LMS di MTs.M Kab. Solok yang terdiri 4 tahap kegiatan yaitu :

1. Konsolidasi, pada fase ini dilakukan konsolidasi dan survey awal ke MTs.M Saningbakar sebagai lokasi kegiatan dan 8 MTs.M lainnya, untuk mendapatkan informasi lebih jauh tentang kesiapan masing-masing madrasah serta penetapan jadwal agenda dalam pengembangan $\mathrm{BL}$

2. Pelatihan BL bagi Guru, fase ini merupakan kegiatan inti pengembangan BL dan penugasan digitalisasi konten bagi guru MTs.M

3. Pelatihan BL bagi Administrator, merupakan kegiatan lanjutan bagi tenaga Administrator BL dalam mengelola dan mengadministrasi BL, yang diambil dari Guru TIK di masing-masing MTs.M.

4. Pelaporan/Analisa Data, digunakan untuk mengumpulkan data berdasarkan alat pengumpul data berupa kuesioner yang diberikan baik sebelum kegiatan maupun setelah kegiatan pelatihan pengembangan BL.

\section{HASIL DAN PEMBAHASAN Hasil Survey dan Konsolidasi}

Dari kegiatan Survey awal dan konsolidasi ini diperoleh hasil sebagai berikut

1. Penetapan MTs.M Saningbakar sebagai Host kegiatan, berdasarkan kesiapan fasilitas TI dan Lab. Komputer, dengan interkoneksi Speedy dan Lab Komputer 30 Unit PC, yang telah digunakan untuk UNBK sejak 2017.

2. Hasil survey awal ke 9 MTs.M, diperoleh data sebagai berikut :

Tabel 1. Data Sekolah Mitra dan Peserta Pelatihan Pengembangan BL berbasis LMS

\begin{tabular}{lll}
\hline Nama MTsM & Guru & Admin \\
\hline MTs. M Saningbakar & 5 Guru & 2 Admin \\
\hline MTs. M Sumani & 4 Guru & 1 Admin \\
\hline MTs. M P.Belimbing & 3 Guru & 1 Admin \\
\hline MTs. M Sulit Air & 3 Guru & 2 Admin \\
\hline MTs. M Paninggahan & 3 Guru & 1 Admin \\
\hline MTs. M Panyakalan & 3 Guru & 1 Admin \\
\hline MTs. M Cupak & 3 Guru & 1 Admin \\
\hline MTs. M Bukit Kili & 3 Guru & 1 Admin \\
\hline MTs. M Muara Panas & 3 Guru & 1 Admin \\
\hline \multicolumn{1}{c}{ Jumlah } & 30 Guru & 11 Admin \\
\hline
\end{tabular}

Pada Tabel 1, jumlah partisipasi MTs.M menjadi 9 MTs dari 8 yang direncanakan, hal ini menunjukkan tingginya antusiasme pihak madrasah dalam pengembangan BL berbasis LMS.

Tabel 2. Analisis TIK dan Akses Internet di 9 MTs.M Kab Solok

\begin{tabular}{lllll}
\hline Nama MTsM & Web & Email & Int & WIFI \\
\hline MTs. M Saningbakar & T/A & A & A & A \\
\hline MTs. M Sumani & T/A & A & A & T/A \\
\hline MTs. M P.Belimbing & T/A & A & A & A \\
\hline MTs. M Sulit Air & T/A & A & A & A \\
\hline MTs. M Paninggahan & T/A & A & $\mathrm{A}$ & T/A \\
\hline MTs. M Panyakalan & T/A & A & $\mathrm{A}$ & T/A \\
\hline MTs. M Cupak & T/A & $\mathrm{A}$ & $\mathrm{A}$ & $\mathrm{A}$ \\
\hline MTs. M Bukit Kili & T/A & $\mathrm{A}$ & $\mathrm{A}$ & T/A \\
\hline MTs. M Muara Panas & T/A & $\mathrm{A}$ & $\mathrm{A}$ & $\mathrm{A}$
\end{tabular}

$\mathrm{A}=\mathrm{Ada}, \mathrm{T} / \mathrm{A}=$ Tidak ada

Tabel 2, memperlihatkan, hamper semua MTs.M belum memiliki alamat domain resmi web sekolah, kalaupun pernah ada, domain tersebut tidak aktif lagi, sehingga untuk komunikasi dan berbagi informasi dilakukan melalui Email dan Sosial media. Sedangkan untuk akses internet, semua Madrasah sdh memiliki akses, namun pada lingkungan terbatas, dan beberapa diantaranya tidak menyediakan fasilitas Wifi.

Pelatihan Blended Learning bagi Guru 
Pelatihan BL diberikan kepada guru dalam mengembangkan BL berbasis LMS, dengan pokokpokok materi utama :

Tabel 3. Rancangan Materi BL

\begin{tabular}{ll}
\hline Materi & Jam \\
\hline Teknologi Informasi dalam Pendidikan & 2 \\
\hline $\begin{array}{l}\text { Blended Learning dan Implementasi dalam } \\
\text { Pembelajaran }\end{array}$ & 2 \\
\hline $\begin{array}{l}\text { Pengenalan Learning Managemenet System } \\
\text { Moodle }\end{array}$ & 4 \\
\hline Pengelolaan Online Class dengan LMS Moodle & 4 \\
\hline Digitalisasi Konten ke LMS Moodle & 4 \\
\hline $\begin{array}{l}\text { Embedded Media (Video, PDF Viewer, Slide } \\
\text { Show) }\end{array}$ & 4 \\
\hline Chat, Tugas, dan Forum Diskusi Online & 4 \\
\hline Kuis, Tes Formatif dan Ujian Online & 4 \\
\hline $\begin{array}{l}\text { Praktikum Mandiri (Pengembangan Blended } \\
\text { Learning Mata Pelajaran) }\end{array}$ & 12 \\
\hline
\end{tabular}

Pelatihan diberikan untuk memberikan penguatan kompetensi dan keterampilan kepada guru dalam implementasi BL berbasis LMS, sebagaimana terlihat pada Tabel 3 terdiri dari 40 jam pembelajaran.

\section{Pembelajaran Blended Learning bagi Admin} Untuk menjamin keberhasilan pengembangan BL berbasis LMS di MTs.M Kab. Solok, maka perlu peran seorang administrator yang akan mengelola online learning secara keseluruhan, dengan rancangan materi sebagai berikut :

Tabel 4. Rancangan Materi BL bagi Administrator

\begin{tabular}{ll}
\hline Materi & Jam \\
\hline Arsitketur LMS Moodle & 2 \\
\hline Instalasi dan Konfigurasi LMS Moodle & 4 \\
\hline Pengantar Administrator Sistem & 2 \\
\hline Pengaturan Halaman Depan LMS & 2 \\
\hline Mangatur Tampilan dan Theme & 2 \\
\hline Pengelolaan Akun Pengguna & 3 \\
\hline Pengelolaan Kategori dan Kursus & 3 \\
\hline $\begin{array}{l}\text { Pengaturan Peran Guru Mata Pelajaran, Guru } \\
\text { Pendamping dan Siswa }\end{array}$ \\
\hline \multicolumn{2}{l}{ Jumlah } \\
\hline
\end{tabular}

Pengembangan BL berbasis LMS dengan Model Instruksional ADDIE

\section{Hasil Analisis}

Analisis kesiapan SDM dan teknologi MTs.M dalam mengimplementasikan BL, dikembangkan menggunakan Framework Digital Skill.

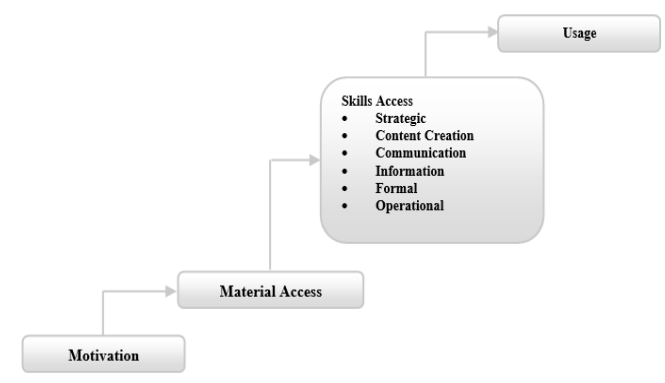

Gambar 3. Framework Digital Skill [13]

Berdasarkan framework tersebut di atas, maka kemudian dikembangkan instrument yang digunakan untuk melihat aspek motivasi, material akses, skill akses dan penggunaan teknologi digital oleh Guru di MTs.M Kab. Solok.

Tabel 5. Data pemetaan kompetensi TIK Guru MTs.M Kab. Solok

\begin{tabular}{lllll}
\hline Kompetensi TIK Dasar & PM & MN & MH & JML \\
\hline Pengoperasian Komputer & 10 & 8 & 6 & 24 \\
Aplikasi Pengolah Kata & 12 & 8 & 4 & 24 \\
Aplikasi Presentasi & 14 & 6 & 4 & 24 \\
Aplikasi Pengolah Angka & 10 & 12 & 2 & 24 \\
Akses Internet & 12 & 6 & 6 & 24 \\
Internet Resources & 15 & 6 & 3 & 24 \\
Online Learning & 20 & 2 & 2 & 24 \\
Integrasi Internet dan TIK & 22 & 2 & 0 & 24 \\
dalam Pembelajaran & & & &
\end{tabular}

$\mathrm{PM}=$ Pemula, $\mathrm{MN}=$ Menengah, $\mathrm{MH}=$ Mahir

Untuk kebutuhan analisis ini, maka dilakukan pemetaan kompetensi dasar TIK para Guru, yang diukur dengan Pre and Post Training Questionnaire design. Sebelum pelatiha kuesioner didistribusikan secara online kepada perwakilan 3 orang guru dari 8 MTs.M mitra setelah survey awal, dan diperoleh hasil seperti pada Tabel 5.

\section{Hasil Perancangan}

Rancangan BL berbasis LMS, dibangun berdsarkan kurikulum MTs yang berlaku, yang dikelompokkan menjadi Kelompok A, B (MTs. Negeri) dan Kelompok Muatan Lokal Kemuhammadiyahan. 


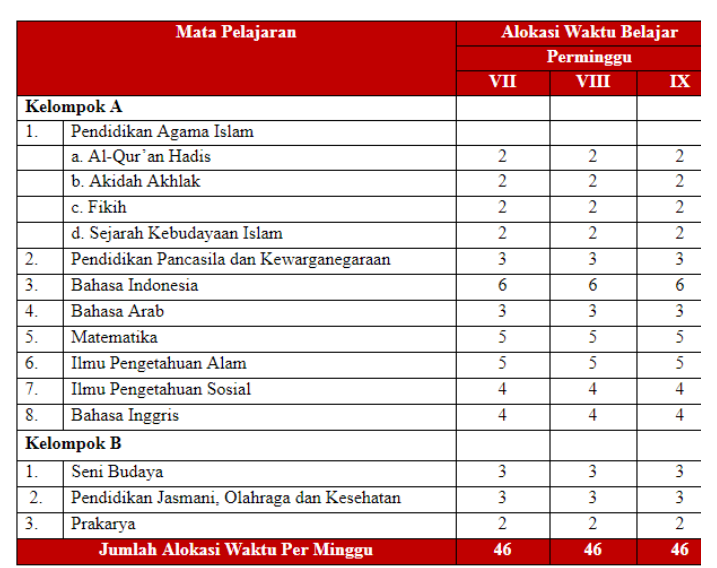

Gambar 4. Kurikulum Nasional MTs.

Maka dirancanglah struktur menu BL berbasis LMS sebagai berikut :

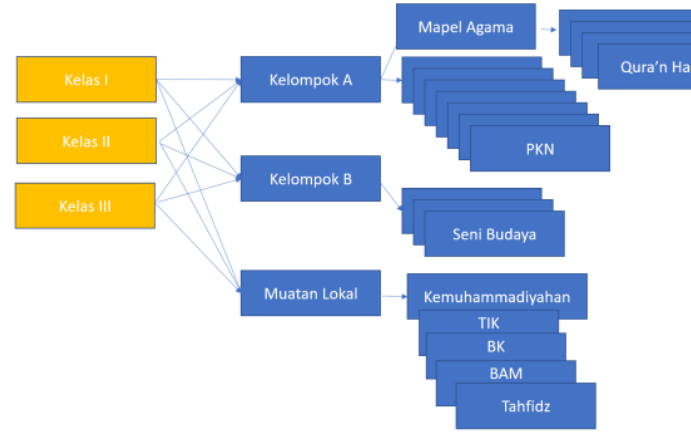

Gambar 5. Struktur Menu BL berbasis LMS

Untuk mengakses sistem BL berbasis LMS, maka dirancang mekanisme aliran akses pengguna, baik guru maupun siswa, seperti terlihat pada Gambar 6, yang dapat diuraikan sebagai berikut: seorang pengguna memulai aktifitasnya pada halaman login, dengan memasukkan username dan password, kemudian LMS mengecek apakah username dan password tersebut, jika data ada, maka login sukses, jika tidak kembali ke halaman login.

Sedangkan untuk rancangan data, mengikuti standar struktur basis data yang ada pada sistem LMS Moodle [19], sebagai sebuah content management system (CMS), sebagaimana terlihat pada Gambar 7.

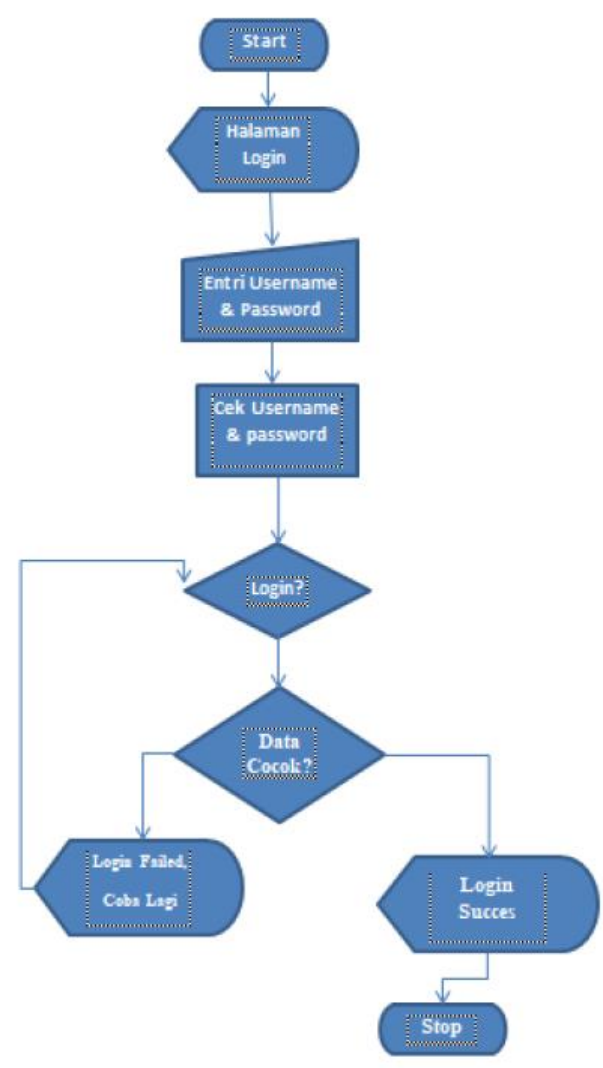

Gambar 6. Flowchart Sistem Login

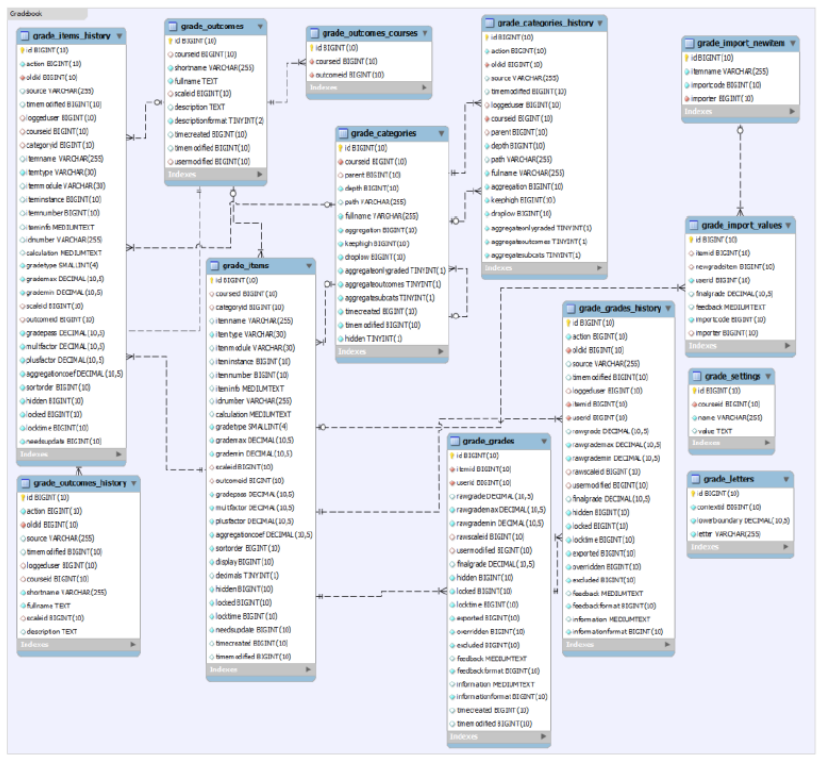

Gambar 7. Struktur Tabel Basis Data Moodle [19]

\section{Hasil Pengembangan}

Berdsarkan hasil perancangan, maka kemudian LMS Moodle di instalasi dan dikonfigurasi sesuai dengan kebutuhan pembelajaran online di MTs. Diperoleh hasil pengembangan sebagai berikut : 


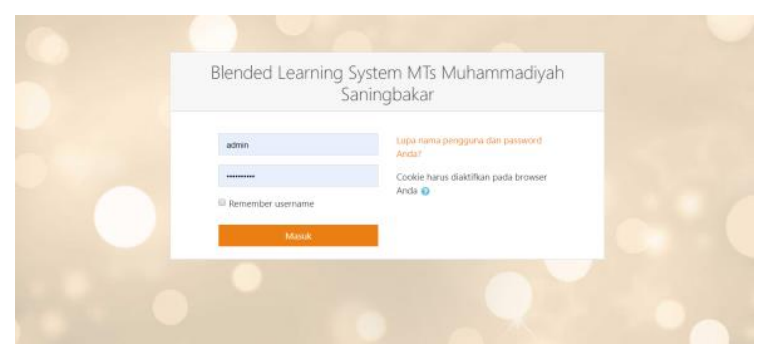

Gambar 8. Halaman Login LMS MTs.M

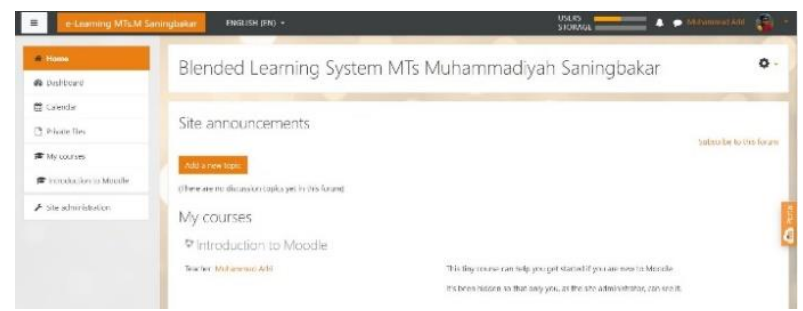

Gambar 9. Halaman Utama LMS MTs.M

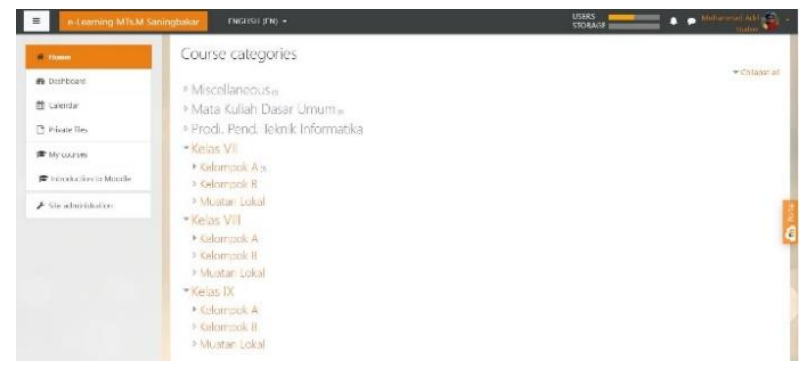

Gambar 10 Halaman Course Category

\section{Hasil Implementasi}

BL berbasis LMS yang telah dirancang dan dikembangkan, kemudian diimplementasikan pada domain dan hosting official masing-masing MTs.M, seperti telihat pada Tabel 6 .

Tabel 6. Daftar Nama Domain MTs.M Kab Solok

\begin{tabular}{|c|c|}
\hline Nama MTsM & Domain \\
\hline MTs. M Saningbakar & http://mtsmsaningbakar.sch.id \\
\hline MTs. M Sumani & http://mtsmsumani.sch.id \\
\hline MTs. M P.Belimbing & http://mtsmpadangbelimbing.sch.id \\
\hline MTs. M Sulit Air & http://mtsmsulitair.sch.id \\
\hline MTs. M Paninggahan & http://mtsmpaninggahan.sch.id \\
\hline MTs. M Panyakalan & http://mtsmpanyakalan.sch.id \\
\hline MTs. M Cupak & http://mtsmCupak.sch.id \\
\hline MTs. M Bukit Kili & http://mtsmbukitkili.sch.id \\
\hline MTs. M Muara Panas & http://mtsmmuarapanas.sch.id \\
\hline
\end{tabular}

Pada implementasi ini, masing-masing guru diwajibkan untuk mengembangkan konten dan mengupload konten pembelajaran salah satu mata pelajaran yang dibina di MTs.M.

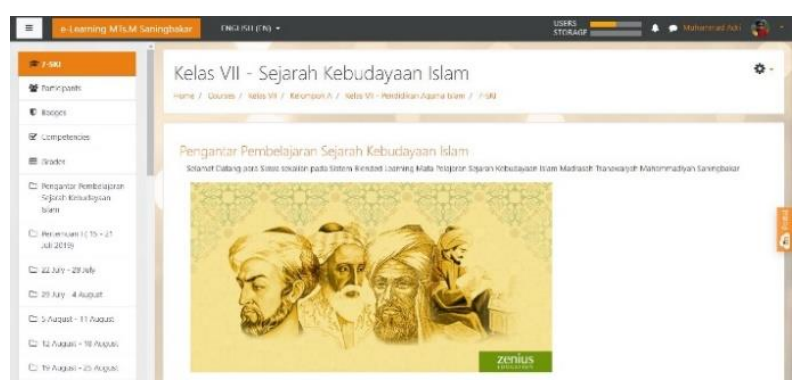

Gambar 11. Contoh implementasi dalam mata pelajaran Sejarah Kebudayaan Islam (SKI)

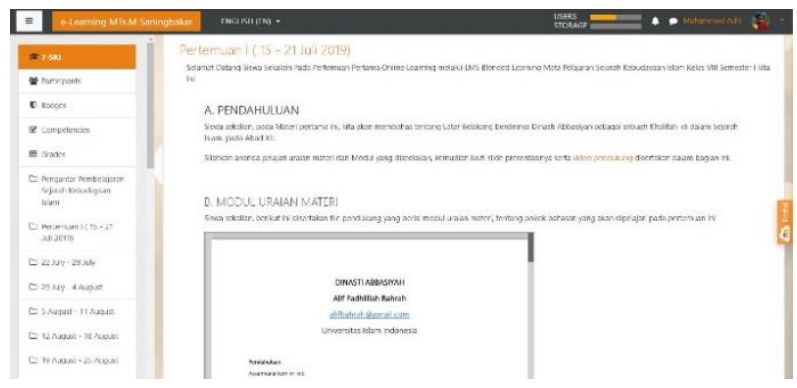

Gambar 12. Learning Resources SKI

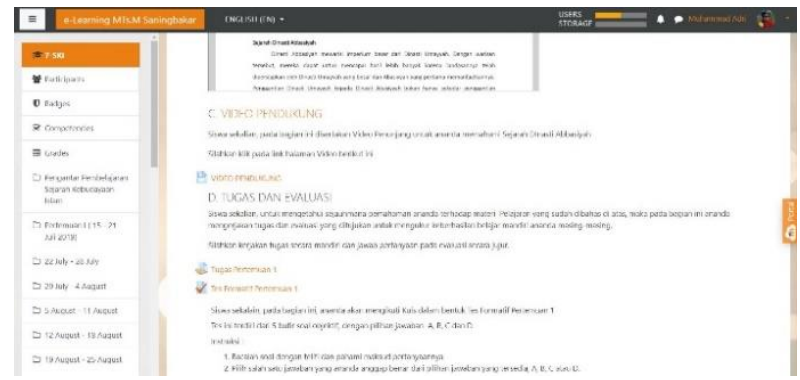

Gambar 13. Learning Activity SKI

Proses implementasi dalam salah satu mata pelajaran masing-masing guru dilakukan secara mandiri, dengan menggunakan LMS Moodle yang diinstal pada sub domain masingmasing MTs.M, sebagai contoh MTs.M Saningbakar memiliki domain :

Domain : http://mtsmsaniangbakar.sch.id Subdomain LMS Moodle dapat diakses pada : http://elearning.mtsmsaningbakar.sch.id

\section{Hasil Evaluasi}

Setelah kegiatan pengembangan BL berbasis LMS selesai dilakukan, dan masingmasing guru menyelesaikan pengembangan konten, maka selanjutkan dilakukan evaluasi. Jumlah peserta yang dievaluasi berjumlah 30 Guru. Evaluasi pertama yang dilakukan adalah peningkatan ketermpilan TIK guru, seperti terlihat pada Tabel 7.

Tabel 7. Data pemetaan kompetensi TIK Guru MTs.M

Kab. Solok

\begin{tabular}{lllll}
\hline Kompetensi TIK Dasar & PM & MN & MH & JML
\end{tabular} 


\begin{tabular}{lllll}
\hline Pengoperasian Komputer & 6 & 14 & 10 & 30 \\
\hline Aplikasi Pengolah Kata & 8 & 14 & 8 & 30 \\
\hline Aplikasi Presentasi & 7 & 15 & 8 & 30 \\
\hline Aplikasi Pengolah Angka & 8 & 16 & 6 & 30 \\
\hline Akses Internet & 6 & 14 & 10 & 30 \\
\hline Internet Resources & 8 & 14 & 8 & 30 \\
\hline Online Learning & 10 & 12 & 8 & 30 \\
\hline $\begin{array}{l}\text { Integrasi Internet dan TIK } \\
\text { dalam Pembelajaran }\end{array}$ & 12 & 12 & 6 & 30 \\
\hline PM = Pemula, MN = Menengah, MH = Mahir
\end{tabular}

Jika dilihat dari framework Digital Skill, pada aspek motivasi diperoleh data sebagai berikut :

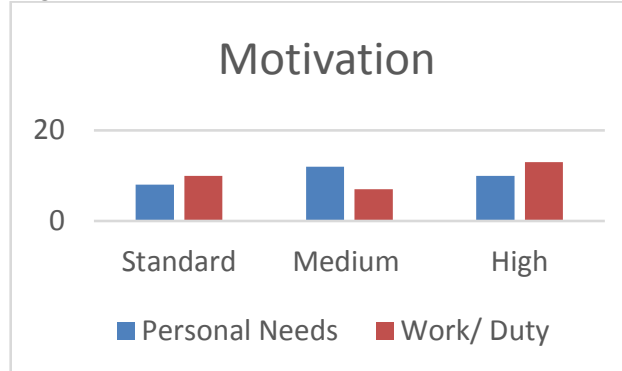

Gambar 14. Perbandingan dalam motivasi pribadi dan kerja dalam menggunakan TIK

Kemudian jika dilihat dari aspek material access, mayoritas guru menggunakan smartphone sebagai alat koneksi internet dan data.

\section{Material Access}

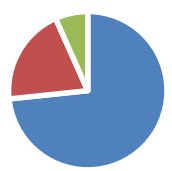

- Smartphone - Wi-Fi on School - Private Wi-Fi

Gambar 15. Pemanfaatan Material Akes oleh Guru

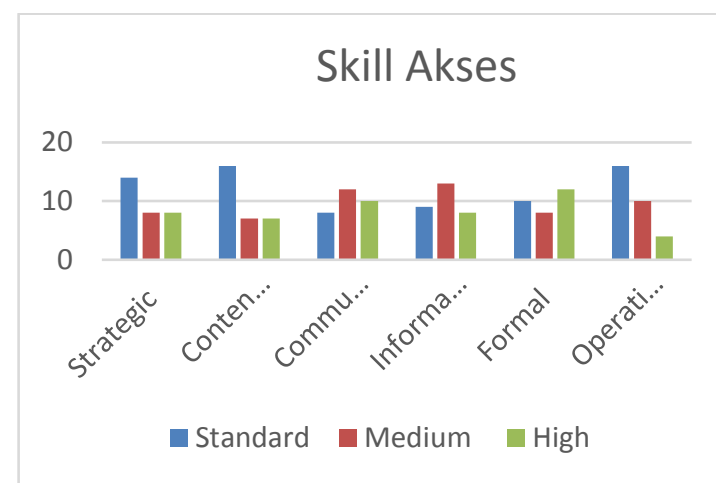

Gambar 16. Skill akses
Pada aspek skill akses ini, dapat dilihat terdapat beberapa kemampuan guru yang harus dibina agar dapat lebih memaksimalkan pemanfaatan TIK dalam Pendidikan.

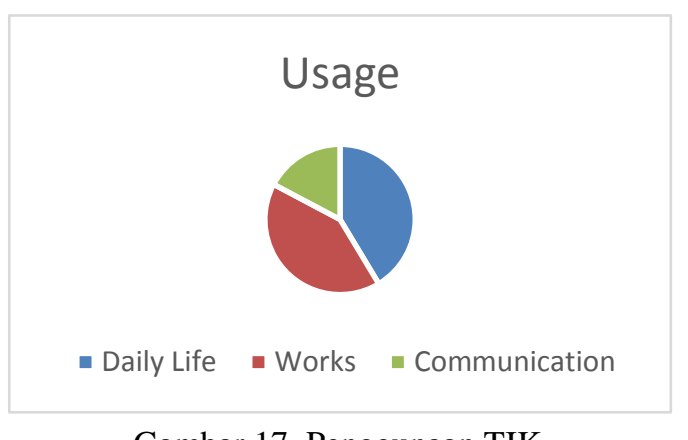

Gambar 17. Penggunaan TIK

Dari aspek penggunakan skill digital/ TIK, maka keterampilan tersebut berimbang dalam kebutuhan kehidupan sehari-hari dan kerja.

\section{PEMBAHASAN}

Berdasarkan hasil analisis dan data yang dperoleh selama pengembangan BL berbasis LMS dapat dilihat kesiapan MTs.M dalam mengimplementasikan BL, bahwa Semua peserta memperoleh keterampilan TIK dengan peningkatan yang signifikan seperti yang terlihat dalam perbandingan Tabel 5 dan Tabel 7. Dari aspek motivasi, dapat dilihat bahwa peserta yang menggunakan TIK didorong oleh kebutuhan pribadi dan tuntutan pekerjaan yang tinggi. Dari aspek akses material, sebagian besar peserta menggunakan perangkat pribadi seperti smartphone sebagai alat dalam mengakses TIK. Pada aspek keterampilan akses TIK, maka pada level strategi akses masih pada level standar, pembuatan konten juga pada level yang sama, serta keterampilan operasional. Penguasaan yang lebih baik terjadi dalam aspek komunikasi dan pemanfaatan informasi yang berada di tingkat menengah, sedangkan akses formal memiliki keterampilan tinggi. Dalam hal penggunaan, ada keseimbangan antara pribadi dan pekerjaan.

\section{KESIMPULAN}

Dari hasil penelitian dan pembahasan tentang pengembangan BL berbasis LMS di MTs.M Kab. Solok dapat disimpulkan berikut ini :

1. Semua Madrasah MTs.M di Kab. Solok memiliki SDM yang siap unruk mengguankan TIK sebagai pendukung dalam pendidikan

2. Dari hasil analisis dengan menggunakan Digital Skill Framework dapat dilihat bahwa 
MTs.M siap dalam mengimplementasikan model BL berbasis LMS.

\section{SARAN}

Pada masa yang akan dating perlu upaya mandiri dari masing-masing MTs.M dalam memaksimal implementasi TIK dalam pembelajaran, khususnya yang berkaitan dengan kompetensi Guru dalam mengembangkan konten dan modul pembelajaran online, video pembelajaran, Teknik evaluasi dan instrument evalusai online.

\section{DAFTAR PUSTAKA}

[1] Kemendikbud RI, Kurikulum Pendidikan Nasional 2013, Kementerian Pendidikan dan Kebudayaan RI, Jakarta, 2014.

[2] Rojko, Andreja, "Industry 4.0 : Concept and Background". International Journal of Interactive Mobile Technology, vol. 11, no.5, pp. 77-90, 2017.

[3] Bogovitz, Aleksei V, et.al, "Comparative Analysis of Formation of Industry 4.0 in Developed and Developing Countries", E. G. Popkova et al. (eds.), Industry 4.0: Industrial Revolution of the 21st Century, Studies in Systems, Decision and Control 169, pp. 155 - 164, Springer International Publishing AG, part of Springer Nature 2019, https://doi.org/10.1007/978-3-319-943107_15

[4] Muhammad Ruslan, Pendidikan di Era RI 4.0 dan Tantangannya, 2019. Website: https://www.kompasiana.com/2220/5aebb94 eab12ae687e7f5153/pendidikan-di-era-ri-40 -dan-tantangannya?page $=$ all diakses tanggal 5 Juni 2019.

[5] Harjanto Probowo, Blunder Paradigma menghadapi Era Industri 4.0, 2018 Website: https://onlinelearning.binus.ac.id/2018/08/02 /blunder-paradigma-menghadapi-eraindustri-4-0/ diakses tanggal 5 Juni 2019

[6] Soekartono,Evolusi 4.0 dan Dampaknya terhadap Pendidikan di Indonesia, 2018. Website: http://fkip.ums.ac.id/wpcontent/uploads/sites/43/2018/12/RevolusiIndustri-4.0-dan-Dampaknya-terhadapPendidikan-di-Indonesia-Dr.-Sukartono.doc, diakses tanggal 5 Juni 2019

[7] Muhammad Adri, Pengembangan Model Blended Learning pada Mata Kuliah Komunikasi Data dan Jaringan Komputer, makalah pada Seminar Internasional Teknologi Informasi dan Pendidikan, Padang, 29 Januari 2011.
[8] Hansi Effendi, "Blended Learning Effectiveness in Improving Learning Access in Higher Education", Advances in Social Science, Education and Humanities Research, volume 299, pp. 298-301, Atlantis Press, 2019

[9] Lukito Edi Nugroho, Pemanfaatan Teknologi Informasi pada Perguruan Tinggi, Gava Media, Yogyakarta, 2010.

[10] Muhammad Adri, dkk, "Pengembangan Model Blended Learning di MTs. Muhammadiyah Saningbakar Kec.X Koto Singkarak Kabupaten Solok", Jurnal Teknologi Informasi dan Pendidikan, Vol. 10 No. 3, 2017, hal. 107-116, DOI : 10.24036/tip.v10i3.25, Website Artikel http://tip.ppj.unp.ac.id/index.php/tip/article/ view/25

[11] Molenda, Michael, In Search of Eclusive ADDIE Model, Published on http://www.ispi.org, May/June 2003.

[12] Branch, Robert M, Instructional Design: The ADDIE Approach, Springer, New York, USA, 2009.

[13] Van Dijk, Jan A. G. M. and van Deuresen, Alexander, Digital Skill, unlocking the Information Society, New Palgrave MacMillan, York, USA, 2014

[14] Kemenag RI, Surat Keputusan Menteri Agama Nomor 207 Tahun 2014 tentang Kurikulum Madrasah, Kementerian Agama Republik Indonesia, Jakarta, 2014

[15] Dirjen Pend. Islam. Surat Edaran Dirjen Pendis No: SE/Dj.I/PP.00.6/1/2015 tertanggal 2 Januari 2015, tentang Pelaksanaan Kurikulm Madrasah, Direktorat Jendral Pendidikan Islam, Kemenag RI, Jakarta, 2015.

[16] Google Trends, Survey dari penggunaan LMS Moodle, Schoology, Dokeos, dan Atutor pada Google Trends 12 bulan terakhir, Website: Google. 2019. (https://trends.google.com) diakses pada tanggal 03 Agustus 2019.

[17] Moodle. 2019. (https://moodle.org) diakses pada tanggal 03 Agustus 2019.

[18] Rice, William, Moodle ELearning Course Development, 3rd Edition: A complete guide to create and develop engaging elearning courses with Moodle, Packt Publishing, Birmingham, UK, 2015. 